\title{
Zoonotic Diseases Identified by the State-Of-The-Art Zoe Project Research in Romania
}

\author{
Cintia COLIBABA*, Anca CRISTINA COLIBABA, Irina GHEORGHIU, Stefan COLIBABA, Ovidiu URSA, \\ Claudia DIN
}

Universitatea de Stiinte Agricole si Medicina Veterinara Ion Ionescu de la Brad din Iasi, Gr. T. Popa University of Medicine and Pharmacy Iasi, Albert-Ludwigs-Universität Freiburg, Universitatea Al. I. Cuza Iasi, Universitatea de MedicinasiFarmacie "Iuliu Hatieganu"Cluj, Gr. T. Popa University of Medicine and Pharmacy Iasi

*corresponding author: cintia.colibaba@gmail.com

Bulletin UASVM Veterinary Medicine 75(1)/2018

Print ISSN 1843-5270; Electronic ISSN 1843-5378

doi:10.15835/buasvmcn-vm:001817

\begin{abstract}
The article is based on the ZOE project, Zoonoses Online Education, (2016-1-R001-KA203-024732), funded by Erasmus+. The project aims to create open digital educational resources in the field of veterinary medicine based on developing innovative guidelines on zoonotic diseases.

The article looks at the main findings of the project's state-of-the-art research in Romania on the 5-10 most encountered and identified zoonoses in the last 10 years at national level.

The project research has evaluated the medical literature on zoonotic diseases in the veterinary field and highlighted a variety of diseases that cover the spectrum of infectious agents and display a variety of transmission patterns in different environments, identifying ways of intervention in the local context. This article looks at the second most spread disease present in the-state of-the-art research, Leishmaniasis.

The analysis will be incorporated into a guide and an open online course guide on main infectious diseases transmitted from non-human animals to humans, including videos capturing zoonoses bio-manipulation in simulation centres. It will also be part of a guide and an open online course on medical communication, including the zoonoses videos processed from a linguistic, cultural and communication point of view, available in six languages.
\end{abstract}

Keywords: zoonoses, state of art research, online course, education.

\section{Introduction}

Zoonoses, infectious diseases that are spread from animals to humans, still pose significant public health risks; outbreaks of such diseases have been signalled recently although they had been considered eradicated and are caused by global warming and people's unprecedented mobility. They affect people mostly from developing countries where certain categories are especially at risk: under five-year-old children, elderly people and people with weakened immune systems. In addition, they can have a negative impact on commerce, travel and the economy. In spite of the threats they represent most of them are neglected at local or national levels. However, WHO has repeatedly sounded the alarm about the necessity of joining forces to combat the international spread of outbreaks among humans [8].

The project ZOE - Zoonoses Online Education (2016-1-R001-KA203-024732) represents the alignment to the international efforts of a multidisciplinary partnership from three educational sectors: veterinary medicine, human medicine and pedagogy education from four countries: Croatia, Italy, Lithuania and Romania. The project 
Table 1: List of zoonoses studiedby each partner

\begin{tabular}{cccc}
\hline $\begin{array}{c}\text { Zoonoses under } \\
\text { study in Ro }\end{array}$ & $\begin{array}{c}\text { Zoonoses under } \\
\text { study in HR }\end{array}$ & $\begin{array}{c}\text { Zoonoses under } \\
\text { study in LT }\end{array}$ & $\begin{array}{c}\text { Zoonoses under } \\
\text { study in IT }\end{array}$ \\
\hline Dirofilariosis & Boreliosis & Salmonelosis & Q fever \\
\hline Malaria & W-Nile fever & E coli & Cat scratch \\
\hline Leishmaniosis & Leptospirosis & E hepatitis & Listeria \\
\hline Trichinosis & Tuberculosis & & \\
\hline
\end{tabular}

aims to create open digital educational resources in the field of veterinary medicine based on developing innovative guidelines on zoonotic diseases; its veterinary, medical, pedagogical and linguistic outputs aim to raise awareness about these diseases and provide target groups with information and tools as to how to identify, monitor and control them; such products address a large audience from academics to professional and general beneficiaries (Colibaba, 2016). Through its activities, the ZOE project meets the needs of a wide variety of people:lecturers, (foreign) students and professionals in the field of veterinary medicine; lecturers, (foreign) students and professionals in the field of medicine (Health Care and Epidemiology); teachers and future teachers, lecturers and students of Pedagogy and public at large (pupils aged 6-12, parents).

Based on the competences and activities in which the direct mentioned target group will be involved, the project has impact on the following indirect target groups: veterinaryuniversities, treatment centres; medical universities, hospitals, clinics of epidemiology; health care organizations and public institutions; patients, families or animals owners/carers; volunteers in the field of human medicine or veterinary medicine; pedagogical universities; schools.

\section{Materials and methods}

The state-of-the-art research in each country identified the 5-10 most frequent zoonoses in the last 10 years at national level.

\section{Arthropod-borne zoonoses:}

1. Protozoonoses: Babesiosis, Malaria, Leishmaniosis

2.Zoonoses produced by helminths: Dirofilariosis

3. Zoonoses produced by bacteria: Boreliosis, Ehrlichiosis, Anaplasmosis, Cat scratch disease, Q Fever, Typhus
4. Zoonoses produced by viruses: West-Nile Fever, Crimean-Congo Fever, Dengue Fever

\section{Food-borne zoonoses:}

1. Protozoonoses: Sarcocystosis, Cyclosporidiosis

2. Zoonoses produced by helminths: Opistorchosis, Echinostomosis, Cestodoses and metacestodoses, Trichinelosis, Anisakiosis, Larva migrans visceralis

3. Bacterial zoonoses: Infections produced by $\mathrm{E}$. coli enterohaemorhagiae (EHEC), Salmonelosis, Anaerobic Enterotoxiemia, Campylobacteriosis, Listeriosis, Tuberculosis

4. Zoonoses produced by viruses: E Hepatitis, Norovirus infection

\section{Water-borne zoonozes:}

1. Protozoonosis: Cryptosporidiosis, Giardiosis, Amibiasis, Cyclosporosis, Fungal diseases, Microsporosis

2. Helminthoses: Bilharziosis, Dracunculosis

3. Bacterial diseases: Vibrio Cholerae Infections, Shigella dysenteriae infection, Salmonelosis

\section{Air-borne diseases:}

1. Bacterial diseases: Chlamydiosis (psittacosis), Tuberculosis

2. Viral diseases: Avian flu, Swine flu

3. Mycoses: Histoplasmosis, Aspergilosis

4. Viroses: Rabia

The research was based on specialized evidence provided by the Public Health organisations in partner countries. A number of 15 zoonoses were selected and specialized research and study on the selected diseases was done within the partnership. 


\section{Results}

The project research has evaluated the medical literature on zoonotic diseases in the veterinary field and highlighted a variety of diseases that cover the spectrum of infectious agents and display a variety of transmission patterns in different environments, identifying ways of intervention in the local context. The research has been based on a structured plan which characterises each disease in terms of its etiology (causes and origins), epidemiology (source and path of infection,geographical distribution, responsiveness, resistance to the environment), pathogenesis, clinical symptoms, diagnosis, prophylaxis and treatment.

The present study focuses on the second most spread disease present in the state of the art research, Leishmaniosis, which has been analysed in detail by collecting information from literature research, indirect interviews with specialists, or examples of best practices on zoonoses education.

Leishmaniasis is an important disease, present in over 88 countries, with 350 million people at risk. WHO reports 1.3 million new cases and around 50,000 deaths every year, a death rate second only to malaria among parasitic diseases [9].

Most of the new cases have been signalled in Latin America, Africa, India, Middle East and Mediteranian region (Gogoașe et al., 2013). In Europe most of the cases that have appeared lately have been imported due to recent mobility, especially travel to India [10]. In Romania, according to the Centralized Information System for Infectious Diseases (CISID) of WHO the disease had the following distribution: one case in 2006, two cases in 2007 and 2008 and one case in 2010. In Romania, the first case was identified in 1912 and in 1954 there was an outbeak of 24 cases in Oltenia, in the south of Romania [11]. Alexa and colab describe a case identified in Iasi in 2013; the patient who had worked in Italy nine months was transferred to Bucharest for treatment (Alexa et al., 2014).

Gaman et al. (2010) present the case of a person infested with L. Donovanii, who had worked in Greece for 14 months. Gogoașe et al. (2013) describe two cases of visceral leishmaniasis in two patients in 2007: a patient from Dolj (region in the south of Romania) who had worked in Italy, and another case from
Iasi who worked in the south-east of Romania where several cases had been reported. Neghina et al. (2009) present three cases of visceral leishmaniasis imported from Spain in the southwest of Romania.

\section{Epidemiology}

Depending on the species of the parasite, there can be three forms of the disease: cutaneous, mucocutaneus and visceral leishmaniasis. Cutaneous leishmaniasis is the most common form and causes ulcers on the most exposed part of the skin that leave life-long scars and disability after they heal. Most of the cases are found in Central and South America. There are few cases in the Mediterranean basin as well. Mucocutaneous leishmaniasis causes the destruction of mucous membranes of the mouth, nose and throat. Most of the cases occur in Bolivia, Brazil, Ethiopia and Peru. Visceral leishmaniasis, also known as kalaazar is fatal if untreated in most cases and is characterized by irregular bouts of fever, weight loss, enlargement of the spleen and liver, and anaemia. Visceral leishmaniasis is the most common type of leishmaniasis found in Europe. Visceral leishmaniasis can be anthroponotic if the etiological agent is Leishmania Donovani. This species of Leishmania is found in the northeast of India, Bangladesh, Nepal and east Africa. Zoonotic visceral leishmaniasis is caused by Leishmania Infantum and is present in China, Central Asia, the Middle East, Central America and the Mediterranean basin [11].

There are around 20 Leishmania species, which are transmitted to humans and other mammals by phlebotomine sandflies [9]. The disease is transmitted through primary vectors (sandflies belonging to either Phlebotomus spp or Lutzomyiaspp), reservoir hosts (domestic dogs, cats, rodents, etc), or non-vectors (e.g., by accidental laboratory infection, blood transfusion, or organ transplantation in rare cases). Transmission of leishmaniases can be either anthroponotic (a disease causing agent carried by humans is transferred to other animals transmitted through contact such as skin to skin transmission or from a human host to another without a reservoir host: in most cases Leishmania Tropica, Leishmania Donovani) or zoonotic (transmitted from animals to humans). 
The vectors for Leishmania Donovani and Leishmania Tropica are present in the south of Europe whereas Leishmania Infantum is more frequent in France and Spain; a few cases have been reported from Paris and the superior sector of the Rhine.

Even though humans, cats, rats and many other mammals can be hosts to Leishmania Infantum, the dog is considered the most important reservoir. The dog can be infected by at least 12 species, but the most important etiological agent of canine leishmaniasis is Leishmania Infantum. In Europe, canine leishmaniasis can also be caused by Leishmania Tropica and Leishmania Major but in most cases Leishmania Infantum is the most important vector in canine leishmaniasis in Europe [11].

Changes in the epidemiology of canine leishmaniasis caused by Leishmania infantum

Leismania Infantum has long been considered a disease typical of tropical and subtropical regions but reports from all around the world have shown that the epidemiology of this disease is changing. Thusautochtonous cases have been found in the south-east of Canada and in the north of Argentina.

In Europe there are many epidemiological studies that show that this disease is spreading more to the north of the continent. Autochtonous cases have been found in the centre of France, north of Italy, Germany and Romania [11].

\section{Prevention}

Measures taken to control the spreading of zoonotic leishmaniasis vary from drastic culling of seropositive dogs, restrictions on the transportation of dogs from one region to another (Brazil) to the use of insecticides or insecticideimpregnated dog collars. However, although such measures have been implemented since the '50s the Brazilian Health Ministry shows an ascending trend of human visceral leishmaniasis and most scientists argue that these measures do not efficiently prevent the transmission of leishmaniasis in a hiperendemic region like Brazil (Heymann, 2012). On the other hand, the use of insecticides (permethrin, deltamethrin, imidacloprid or piriproxyfen) or insecticideimpregnated dog collars have proved to be more reliable strategies for controlling canine visceral leishmaniasis (Heymann, 2012).
General prevention relies oncontroling vectors (personal protection, use of nets, insecticides, repellants, etc), education of community or early diagnosis of the disease accompanied by effective treatment. Personal protection can be achieved by using nets, repellants or wearing long trousers and long sleeved clothes (Dondorp et al., 2017).

The production of new vaccines against leishmaniasis is slow and difficult. The complex interactions between this parasite and the immune system of its host is the reason why only two vaccines have been produced so far: Leishimune, first produced in Brazil, a vaccine that uses a glycoprotein purified from Leishmania Donovani called fructose mannose ligand(FML) as an antigen mixed with Quil Asaponin as adjuvant (80\% clinical efficacy) and Cani Leish, the first licensed vaccine for canine leishmaniasis in Europe, based on an excreted/secreted protein (ESP) antigen purified from a culture of Leishmania Infantum. It uses QA-21 saponin as adjuvant (68\% clinical efficacy).

\section{Diagnosis}

Diagnostic tests for leishmaniasis (such as the examination of tissue specimens or blood tests that detect antibodies, an immune response to the parasite) are done in order to confirm the disease in patients with clinical symptoms. One of the oldest diagnostic methods is the detection of amastigotes in cutaneous lesions, spleen, bone marrow and lymph nodes. Although it is fast and cheaper than other methods it has a low sensitivity asa low number of parasites may be detected even in dogs with clinical symptoms. A histological analysis of a biopsy from affected tissues can also be used to detect amastigotes but its sensitivity is as lowas the cytological examination's and it also takes more time.

The isolation of parasites from infected tissues is feasible only for research purposes because it is expensive, it is time consuming and it is less sensitive than PCR (polymerase chain reaction) and serology. Serological tests and PCR are the most useful diagnostic methods used for the diagnosis of leishmaniasis. Quantitative serological techniques such as enzyme-linked immunosorbent assay (ELISA) and immunofluorescence antibody test (IFAT) can be used to detect antileishmanial serum antibodies. 
Clinicians should take into account that all serological tests can have false positive results due to cross-reactivity with other pathogens like Trypanosoma Cruzi. High levels of antibodies confirm the diagnosis of leishmaniasis but in the case of low levels, the diagnosis has to be confirmed by other methods such as cytology, histopathology or PCR. PCR is the most sensible and specific method for the diagnosis of leishmaniasis. There are three different PCR techniques available for diagnosis: conventional PCR, nested PCR and realtime PCR. Real-time PCR is the most sensitive and specific method available and it can be used to quantify the presence of Leishmania in tissues. The clinician should take into account data from the clinical evaluation as well as the diagnostic tests.

\section{Treatment}

The most commonly used drugs for the treatment of canine leishmaniasis are: meglumine antimoniate, aminoside, miltefosine, amphotericin $B$, liposomal amphotericin B, metronidazole, and marbofloxacin.

The combination of meglumine antimoniate with allopurinol is considered the most effective and constitutes the first step in the treatment. However, there may be side effects: for instance the risk of renal failure is increased as meglumine antimoniate is nephrotoxic. Because of this side effect miltefosine in combination with allopurinol has been suggested as an alternative to the meglumine antimoniate and allopurinol treatment.

Amphotericin B is the most commonly used drug for human visceral leishmaniasis in Europe but it is not recommended for veterinary use to avoid drug parasite resistance. Amphotericin B also has the disadvantage of being nephrotoxic.

The response to treatment can vary a lot as some patients might show clinical improvement in a month while others require a much longer period of time. Besides monitoring the clinical state of the patient, it is recommended performing blood tests, biochemical profile and urinalysis. These tests should be repeated often during the treatment. The treatment is finished only after a complete clinical recovery signalled by physical examination and blood tests, biochemical profile and urinalysis.

\section{Conclusion}

The findings of the state-of-the-artresearch will be incorporated into a guide and in an open online course guide on main infectious diseases transmitted from non-human animals to humans, including videos capturing zoonoses biomanipulation in simulation centres. It will also be part of a guide and an open online course on medical communication, including the zoonoses videos processed from a linguistic, cultural and communication point of view, which will be available in six languages.

Acknowledgments. This research did not receive any specific grant from funding agencies in the public, commercial, or not-for-profit sectors.

\section{References}

1. Alexa T, Luca A, Cracana I, Onutu R, Merticariu A, Danila C (2014). Leismaniasis - an unusual cause of splenomegaly in Romania. Rev Med Chir Soc Med Nat, 118: 101-106.

2. Colibaba A, Colibaba S, Colibaba C (2016). The ZOE project: Innovative steps in zoonoses online education. Proceedings Lucrări Ştiinţifice, seria Agronomie, 59: 250254.

3. Dondorp AM, von Seidlein L (2017). Leishmaniasis. (4th ed.). In: J. Cohen, W. G. Powderly \& S. M. Opal (Eds.), Infectious Diseases, Vol I (pp. 1015-1064). Elsevier.

4. Gaman A, Dobrea C, Gaman G (2010). A case of visceral leishmaniasis in Oltenia región (Romania). Rom J Morphol Embriol, 51: 391-394.

5. Gogoașe MG, Teodorescu I, Preda C, Ionescu SC (2013). Two case reports on visceral leishmaniasis diagnosed in Romania. Rom Arch Microbiol Immunol, 72: 4955 .

6. Heymann DL (2012). Manual de Management al Bolilor Transmisibile. Un raport oficial al American Public Health Association (19th ed.) (pp. 251-267). Bucarest: Editura Medicală Amaltea.

7. Neghina R, Neghina AM, Merkler C, Marincu I, Moldovan R, Iacobiciu I (2009). Importation of visceral leishmaniasis in returning Romanian workers from Spain. Travel Med Infect Dis, 7: 35-39.

8. Centralized Information System for Infectious Diseases (CISID). WHO Regional Office for Europe. Romania Leishmaniasis. http://data.euro.who.int/ cisid $/$ ?TabID=415710).

9. European Centre for Diseases Prevention and Control. Annual Epidemiological Report 2015. Malaria Stocholm, ECDC, 2016. 
10. World Health Organisation, Zoonosesand the HumanAnimal-Ecosystems Interface, http://www.who.int/ zoonoses/en/
11. World Health Organisation. Leishmaniasis, http://www. who.int/mediacentre/factsheets/fs375/en/ 